\title{
BARRIERS FACED BY THE FRONTLINE HEALTH WORKERS RELATED TO HEALTH COMMUNICATION STRATEGIES UNDER NATIONAL HEALTH MISSION (NHM) IN CHHOTAUDEPUR DISTRICT OF GUJARAT*
}

\author{
Dr. Megha Sidhpura \\ Dr. Anjali Pahad
}

* It is a part of Unpublished Ph.D. Thesis titled as 'Health Communication Strategies under National Health Mission in Chhotaudepur District of Gujarat State' Important permission for data collection was taken from State Health and Family Welfare Department, Gandhinagar and Chief District Health Officer, Chhotaudepur. The investigator had also taken written consent from all respondents before executing questionnaire and Focus-Group Discussion. Financial support: the present research was partially supported by the Research and Consultancy Cell, The Maharaja Sayajirao University of Baroda, Vadodara, Gujarat, India.

\begin{abstract}
Health Communication is an integral component of the National Health Mission used for promotion of health programmes and healthy behaviour amongst the communities. According to the Ministry of Health and Family Welfare, GoI (2019) a strategic framework for targeted IEC activities using 360-degree communication approach is designed.

The Present research was undertaken in a tribal district of Gujarat state-Chhotaudepur to study the barriers related to Health Communication Strategies by the Frontline Health Workers and therefore, a combination of descriptive and analytical methods to explore and describe the existing situation of Health Communication Strategies was adopted. This paper describes about qualitative aspect of the research conducted through total twelve Focus Group Discussions i.e. two in each block (Chhotaudepur, Kawant, Naswadi, Bodeli, PaviJetpur and Sankheda) in which 74 ASHAs, 31 ASHA Facilitators and 34 Female Health Workers. Theme guides was used for FGDs.

Results and discussion are illustrated on central themes of research. Data illustrated that majority of the ASHAs faced moderate barriers and significant differences level barriers were reported by those who belonged to Bodeli, having excellent occupational skills, with low knowledge about Health Communication Strategies and average media use expressed
\end{abstract}


Towards Excellence: An Indexed, Refereed \& Peer Reviewed Journal of Higher Education / Dr. Megha Sidhpura \& Dr. Anjali Pahad / Page 482-495

more barriers than their counterparts. Barriers related to availability, accessibility and characteristics of beneficiaries for Health Communication Strategies were faced to great extent by ASHAs and ASHA Facilitators, however, FHWs expressed barriers related to increase in workload due to duplication of data entry at multiple levels and teething problems in $\mathrm{TeCHO}$,

In a nutshell, results conclude that despite knowing the fact that Health Communication has a significant role to play, this component of NHM is neglected. Hence, the findings demand serious attention on the part of NHM officials and media experts who are the custodian of the community process component of NHM and also academicians and researchers who can also contribute immensely. It is suggested to pay utmost importance and adopt to evidence-based scientific approach for design, production and provision of tailormade, useful and effective Health Communication Strategies for grass-root level health workers and volunteers to foster communication efforts in improving on social determinants of health, achieving behavioural change.

Keywords: Barriers, Health Communication Strategies, National Health Mission, Chhotaudepur-tribal district, ASHA, ASHA Facilitator, Female Health Worker, Frontline Health Workers

\section{Introduction}

Health Communication and National Health Mission (NHM) in India:

Health Communication is an integral component of National Health Mission. In present research Health Communization Strategies is operationally defined as combination of Health Communication tools-techniques (interpersonal, mid and mass media) broadly known/mentioned as IEC and Health Information Technology system (TeCHO mobile, emamta, SATCOM etc.) broadly known/mentioned as ICT used and mentioned under NHM for the purpose of creating awareness, promoting, motivating, escorting, mobilising community people for availing health services, bringing desirable behavioural change, capacity building and strengthening health machinery and Health Management Information System across all stakeholders.

The Ministry of Health and Family Welfare has designed a strategic framework for targeted IEC activities using 360-degree communication approach. All possible means of media including mass media, mid-media and inter-personal activities are used to disseminate information about various health schemes. The Media Plan was monitored at the highest level 
Towards Excellence: An Indexed, Refereed \& Peer Reviewed Journal of Higher Education / Dr. Megha Sidhpura \& Dr. Anjali Pahad / Page 482-495

to ensure due implementation, mid-course correction, and possible change in the focus to suit the needs. (Chapter-17, IEC, Annual Report 2018-19).

The State IEC team is responsible for overseeing the planning, implementation, monitoring, and evaluation of IEC activities, Special Campaigns, Health Education in emergency, monitoring of activities and capacity building of staff at the districts and block levels, and front-line health service providers in communication.Integration of the IEC activities would improve overall coordination, more cost effective and timely utilization of funds, avoid duplication of resources, and strengthen planning, implementation and feedback. IEC activities are especially implemented through District IEC Officers in all 33 districts with special focus in tribal districts in Gujarat.

Health Communication and Frontline Health Workers under National Health Mission (NHM) in India:

From district to grassroot level a system of health communication activities is established. Accredited Social Health Activists (ASHAs), ASHA Facilitators and Female Health Workers (FHWs) perform their duties as Frontline Health workers besides other support structure under Community Process-a component of National Health Mission (NHM). ASHAs act as a link worker, service extension worker and a depot holder. ASHA Facilitators' role is to support ASHA during her work. Female Health Worker is based at subcentre to attend step in patients, and also responsible to convene Village Health Nutrition Day in a village, which is a monthly activity wherein she carries out vaccination and provides ANC services, conducts counselling session and contraceptive services to eligible couples. The one of the objectives of present research was to find out barriers related to Health Communication Strategies faced by the frontline health workers under NHM in Chhotaudepur district, Gujarat state in India.

\section{Methods and Materials}

The research was undertaken in a tribal district of Gujarat state-Chhotaudepur. this total twelve Focus Group Discussions were held i.e. two in each block in which 74 ASHAs, 31 ASHA Facilitators and 34 Female Health Workers took active part. A theme guide was prepared for effective conduct of FGDs. Firstly, data were transcribed and content analysis method was used to derive to conclusion. 
Towards Excellence: An Indexed, Refereed \& Peer Reviewed Journal of Higher Education / Dr. Megha Sidhpura \& Dr. Anjali Pahad / Page 482-495

\section{Results}

Responses of the ASHAs during FGDs to Barriers related to Health Communication Strategies:

In the Focused Group Discussions, ASHAs were asked about the barriers if they face related to Health Communication in their work. From the review of the transcriptions, two major issues were reflected in the responses i.e. barriers related to features of Health Communication Strategies and characteristics of beneficiaries for use of Health Communication Strategies.

Responses of the ASHAs to Barriers related to Features of Health Communication Strategies:

The ASHAs reflected upon barriers they faced related to the implementation of Health Communication Strategies. Villagers, especially children tear posters/charts pasted on walls. They represented their concern for use of local words/terminologies in the media prepared for Tribal people of their area. They emphasised upon it by saying,

'Villagers would understand better if local terminologies and easy language are used.'

Moreover, while discussing pictures and graphics used in health communication media it was reported that present Chart/Poster/wall painting etc. lacked in local tribal representation with regards to graphics, pictures, local terminologies etc. These all factors act as barriers for the ASHAs while using such media with tribal people.Therefore, local representation was emphasised for bringing better concept clarity and easy association with personal level health concerns.

Another barrier was observed in the discussion regarding the size of the Mamta card. The previous Mamta card given was sufficiently bigger and appropriate to enter records in it. But the revised Mamta card is smaller comparatively. Entering information is quite difficult and chances of losing the Mamta card by mothers are high as its look is almost similar to ration card and bank passbook.

There existed mixed responses for the Mamta card (health cards). Some of them inhibited risk for losing it due to its size and appearance. They experienced difficulty in entering details into it. They were in favour of earlier cards with comparative larger size with large pictures and more space to write details. However, some of them favoured small-sized Mamta card as it can be accommodated even in a small purse. 
Towards Excellence: An Indexed, Refereed \& Peer Reviewed Journal of Higher Education / Dr. Megha Sidhpura \& Dr. Anjali Pahad / Page 482-495

Overburdening workload was mentioned as an extreme level of a barrier by the ASHAs, which limit this use of Health Communication Strategies. To quote the ASHAs,

'Work keeps on increasing, they (officers) insist us to do everything in the village.'

It was deliberated by the ASHAs that for any and everything targeting villagers (other than prescribed roles under ASHAs programmes) officers approach to the local ASHA and remain dependent on them only. Even though they were not salaried staff. The ASHA is primarily the grass-root level health activist but in reality, they were expected to do too much of other jobs which leads to somewhere compromise on her actual health promotional and behaviour change activities through using appropriate Health Communication Strategies.

ASHAs were asked about the challenges they faced during the Health Communication Strategies implementation in their allocated villages. They responded that they were provided posters and leaflets about health-related issues of women which they use to communicate with people. They realised that the pictures on the posters and leaflets were outdated, torn and it was difficult to relate with the women of the villages. Also, the posters were in Hindi or Gujarati language, which is slightly different from the local language they use in daily communication. Hence, they suggested that it would be good if they get posters and handbooks in the local language.

The National Health Mission (NHM) provided posters and facilitated wall paintings to be made on the external wall of Anganwadi for the awareness of people, were less in number. They emphasised that more such posters and wall paintings need to be put up everywhere in the village such as school, panchayat office, dairy etc.,

Further, ASHAs also showed concern that the posters with glue do not sustain for a longer period on the wall or sometimes children tore them. Hence, painting the same picture and content on the wall was suggested by them for more durability and visibility.

Although the investigator took enough precautions for not to get the discussion diverted towards payments (remunerations) made to the ASHAs for their work. But in all the blocks during FGDs, ASHAs unanimously with unsatisfied tone raised their voice for their remuneration. They all reported their payment as a barrier or hurdle.

'work is increasing day by day, but not the salary/incentives'

It was expressed intensely during the interaction, that most of the ASHAs do their work with full commitment, they were paid very less and they were overloaded with work. They put up their demand for pay-fixation and an increase in their monthly income. They added that payment of remuneration was very irregular and uncertain and Government should resolve their issue. However, as per Vickey (17, October 2017), Oneindia.com, 'Following 
Towards Excellence: An Indexed, Refereed \& Peer Reviewed Journal of Higher Education / Dr. Megha Sidhpura \& Dr. Anjali Pahad / Page 482-495

the approval of the 7th Pay Commission, the Gujarat government announced a 50 per cent salary hike for Accredited Social Health Activist (ASHA) workers in the state.' It might be they were still not paid as per $7^{\text {th }}$ Pay Commission.

'any new government programme or scheme launched in the village; officers would always call us.'

Many ASHAs shared that they need to be ready at any time of the day for the call from the village people. They did not have fixed timings of work or a holiday in this work. They shared incidences where they had to live with a pregnant woman in the hospital for 3-4 days. (A few of the ASHAs had to take brunt from their families for staying away from their home.)

Inadequate resources were also realized the crucial concern by the ASHAs, ASHA Facilitators and FHWs especially for ASHA diaries, Mamta cards and Registers. Moreover, the number of flipbooks, posters were not sufficient for all ASHAs. Besides these, electricity issues were found in some of the Aanganwadis.

Responses of the ASHAs to Barriers related to Characteristics of Beneficiaries for use of Health Communication Strategies:

Some of the ASHAs reported that families were not cooperative when they were called for meetings at Aanganwadi also were not ready for vaccination of their kids and pregnant women of their family.

'Women do not even remember their LMP (Last Menstrual Period) date.' - As expressed by the ASHAs in a depressing tone.

This means women remain ignorant and less concerned about their reproductive health. They still follow certain myths and wrong beliefs. Reluctant behaviour was a major barrier in the community which hinder behaviour change, availing health benefits and improving the overall health status of a community.

ASHAs shared that sometimes people do not come for vaccination for their child due to their superstitions that child will get sick, also while sterilization campaign, many people had religious beliefs and so they refuse to participate. Families did not allow to write/paint, put up a poster on exterior walls of their house not even simple small sign of polio vaccination done for the household. Therefore, the ASHAs expressed that this kind of experiences with beneficiaries lowered their interest in using Health Communication Strategies. 
Towards Excellence: An Indexed, Refereed \& Peer Reviewed Journal of Higher Education / Dr. Megha Sidhpura \& Dr. Anjali Pahad / Page 482-495

Responses of the ASHA Facilitators during FGDs to Barriers related to Health Communication Strategies:

Thematic analysis of the responses of ASHA facilitators emerged two trends of findings viz, barriers related to characteristics of Health Communication Strategies and characteristics of beneficiaries for use of Health Communication Strategies.

Responses of the ASHA Facilitators to Barriers related to Characteristics of Health Communication Strategies:

Majority of ASHA facilitators faced problems related to power-cut off and poor mobile network connectivity. It has frequently happened in some of the interior village areas. They faced problems in contacting doctor, ambulance or family due to poor connectivity of mobile coverage.

Majority of them had dissatisfaction on regular and sufficient supply of Mamta card, ASHA diary and registers, therefore they had to manage on their own and maintain all the records. They reported their dissatisfaction by,

'for such long time we have not received ASHA diary or registers... we purchase

notebooks/diary on our own'

Some of them were not satisfied with the new design of Mamta card. They expressed that earlier, Mamta card had a picture of mother and child, now they come in orange cover, due to which mother's picture is not visible.

'New design of Mamta card is not appealing since it does not have any pictures of Mother-Child on the cover page.'

Moreover, they reported about problem-related to the timing of SATCOM programmes. According to ASHA Facilitators from Chhotaudepur, the timing of SATCOM program clashes with the timings of the vaccinations on Tuesdays so they cannot watch at all and suggested for changes in the days of broadcast.

The majority of the ASHA Facilitators in all six blocks expressed on the unavailability of uniform, ASHA kit and TeCHO mobile in a complaining tone,

'ASHAs are provided with a uniform and ASHA kit and similarly, FHWs have a uniform and TeCHO mobile. They have not given any such support to us.'

This means that the Facilitators were deprived of uniform which helps in creating identity amongst beneficiaries and health department. Since they were not provided with ASHA Diary, registers nor TeCHO mobile, they faced difficulty in performing her roles during a home visit, record keeping and sharing them with FHWs. 
Towards Excellence: An Indexed, Refereed \& Peer Reviewed Journal of Higher Education / Dr. Megha Sidhpura \& Dr. Anjali Pahad / Page 482-495

Responses of the ASHA Facilitators to Barriers related to Characteristics of beneficiaries for use of Health Communication Strategies:

ASHA Facilitators shared that some people still follow superstitions and myths. They (in-laws) restrict their daughter-in-law for seeking health care and going to health facilities. They did not allow treatment of high-risk mother; vaccination of children. Even when they come for the first dose then in case of fever, they do not complete the next dose. Parents due to their pre-occupied farm work and also due to migration miss on the complete dose of vaccination. It was also reported that parents in their area were ignorant towards illness and poor health of their child, they were not much bothered about it.

ASHA Facilitators shared that some parents did not take their children to hospital due to their belief that the child would not be cured. A case of flat foot child was shared, whose mother lost hope; while ASHA Facilitators, encouraged her to visit a hospital and after treatment, the child got perfectly fine and began to walk properly.

One of the ASHA Facilitators shared that they always maintained the confidentiality of a patient otherwise community people may reject them(patients) from many social

gathering and special occasions. So, in some part of the district, rigid social mentality still prevails.

Responses of the Female Health Workers to Barriers related to Health Communication Strategies:

Female Health Workers were asked about Barriers they might have faced related Health Communication Strategies in Chhotaudepur. Their responses were analysed and two themes have emerged. Their responses are listed as verbatims and described in this section.

Responses of the Female Health Workers toBarriers related to Characteristics of Health Communication Strategies:

FHWs reflected on challenges concerning TeCHO mobiles. They expressed that, 'Maximum barrier we face are related to-Technology'

There were teething troubles encountered during operating it. There were mixed and contradictory responses amongst the group of FHWs regarding various modes of data entry, record keeping and Health Management Information System (HMIS).

Some of them reported that with regards to maintaining manual records (register), E-Mamta portal and now recently TeCHO mobile have made their task repetitive, tedious and hence overloaded. They found it difficult in maintaining the records for DPT and PENTA vaccines 
Towards Excellence: An Indexed, Refereed \& Peer Reviewed Journal of Higher Education / Dr. Megha Sidhpura \& Dr. Anjali Pahad / Page 482-495

for a child and such other details for the family in it. Although the TeCHO application was operated in entire state, there were problems in maintaining details of migrant families within the state across the district.

FHWs mentioned about the repetition of details at three places i.e. register, E-Mamta portal and TeCHO mobiles. They suggested that a decision should be taken fast and anyone format for data entry should be adopted. They stated the need for separate register for number four and five.

According to FHWs, they faced difficulty especially in case of emergency due to network issues, and so they had to keep registers that consume more time as compared to the phone. FHWs shared that in TeCHO mobile if due to any technical reason they could not log in for the day, this information was sent to Gandhinagar, for which they would be required to give explain to officers. The smartphone enables the health department to keep a track of the real-time location of each FHW and the data filled in by her about health aspects i.e. ANC, PNC, Vaccination, fertile couples, leprosy cases etc.

FHWs explained elaborately about the problems they face with the TeCHO mobile like data entry for vaccines, migrant families, retrieval of data, maintaining their home visit schedule etc. This needs to be resolved on an urgent basis since its repercussions are many folds.A high majority of the FHWs expressed their concern regarding the supply of registers to be on time and in sufficient quantity for all 1-8 number registers.

Responses of the Female Health Workers to Barriers related to Characteristics of Beneficiaries for Use of Health Communication Strategies:

FHW shared the difficulty they faced to deal with the people with religious beliefs, who did not get agree to them and did not allow them to visit their place, even after calling them for Mamta divas and giving explanation about vaccination, examples of other children still they did not get convinced, not even allow them to write details in a register. When FHW recorded information in $\mathrm{TeCHO}$ mobile, some beneficiaries expect and inquire about monetary benefits they would get after providing information.

ASHA Facilitators and FHWs Initially used to put ASHA's number in the case when the beneficiary's family did not possess own contact number for any health records. But then TeCHO system did not allow to enter ASHA's number repetitively. So, in that case, they added the number of the beneficiaries' neighbour, who might not be aware of any healthrelated details like vaccination, ANC etc. When Higher authorities from Gandhinagar called to check with the status of vaccine or any other health-related benefits, the neighbour would 
Towards Excellence: An Indexed, Refereed \& Peer Reviewed Journal of Higher Education / Dr. Megha Sidhpura \& Dr. Anjali Pahad / Page 482-495

not be aware and might give the wrong answer. In such a situation, blame came on grass root level health care workers i.e. ASHA, ASHA facilitator and Female Health Worker. So, after narrating this whole situation they suggested to take out a technical solution for the smooth functioning of TeCHO-mobile.

\section{Discussion:}

Major findings revealed that majority of the selected ASHAs faced barriers to a moderate extent, however, data reflected that they faced barriers to an extreme level (great extent) related to availability, features, accessibility, personal and beneficiaries' characteristics while using Health Communication Strategies.

It was found that the ASHAs belonging to Bodeli block, with excellent occupational skills, low knowledge regarding Health Communication Strategies and Moderate level of personal media use, faced significantly more barriers than their counterparts. They were also found to have a high level of perception towards the benefits of Health Communication Strategies. This means they expect more from such health-promoting activities. When their expectations are not fulfilled because of any reason they probably have reported barriers to a great extent.

Further, it can be inferred that the ASHAs with excellent Occupational skills may be very well aware of her role performance effectively using more Health Communication Strategies, any situation adverse to it may lead to internal conflicts and dissatisfaction. Therefore, they face more barriers.Kaur et al. (2017) in their study found that 'inadequate capacity building, poor record-keeping and reporting had an adverse effect on the performance of SaksharMahilaSmooh (SMS) in some of the districts'

The ASHAs whose personal media use was moderate may be experimenting with the use of Health Communication Strategies on the field. While doing so, they might have faced more barriers related to it and therefore they would have expressed barriers related to Health Communication Strategies significantly more than their counterparts.

Chib et al. (2012) in their study documented that 'beyond basic access issues, infrastructural, social, technological and economical barriers to mobile phone adoption existed.' According to Murthy and Vijayraman (2012), heavy workload and Nkanunye and Obiechina (2017) low health literacy and poor communication were the barriers before Health Workers.So, if the supply of resources (ASHA diary, Mamta card etc.) are not made available on time then it becomes a major cause of concern for Programme and Policy planners. Thakur et al. (2017) concluded that 'IEC/BCC/HP is a neglected area in national health programmes in the 
Towards Excellence: An Indexed, Refereed \& Peer Reviewed Journal of Higher Education / Dr. Megha Sidhpura \& Dr. Anjali Pahad / Page 482-495

selected districts with an inadequate budget, human resources with poor implementation and requires strengthening for better implementation of the national health programmes. The low morale of programme officers and lack of importance given to the IEC component in the programme was a threat.' Kaur et al. (2017), suggested 'better planning and monitoring can improve programme performance.'

Beneficiaries are the actual target of all health programmes. Their openness, readiness and acceptance for betterment are crucial ingredients of successful Health Communication activities. It was reflected by the ASHAs, ASHA Facilitators and Female Health Workers as a barrier, that some of the beneficiaries remained reluctant and follow wrong beliefs, which acted as a major challenge before them for flawless implementation of Health Communication Strategies.

Barriers related to authorities were found to have intensity at a moderate level. This may be due to ASHAs' respect towards higher authorities and officers or maybe they are afraid of expressing their real feeling about their superiors.Officers should act as a motivating force to ASHA, who work tirelessly for delivering health services.

ASHA facilitators reflected upon certain barriers with regards to infrastructure i.e. electricity supply, network coverage and social dynamics like superstitions and myths. During FGDs they expressed needs related to Health Communication Strategies, specifically additional strategies and training needs. They explained that they are the only group who are not given any uniform.

Female Health Workers expressed their barriers with regards to duplication of data entry in registers, e-Mamta and TeCHO mobile. They faced teething problems in TeCHO mobile for vaccination module and details of family migrants, which they requested to look into it and resolve.

Overall Findings indicate that the ASHAs, ASHA Facilitators and Female Health Workers need to be supported well in process of overcoming all sorts of barriers viz. features, availability and accessibility of Health Communication Strategies, personal level barriers and barriers related to beneficiaries. The policy planners, media practitioners, NGOs consultants and other stakeholders need to be involved in rigorous planning, execution and monitoring of strategies Health Communication Strategies. This process should overcome a limited variety, size, local representation through visual and terminologies.

The ASHAs, ASHA Facilitators and Female Health Workers need to be trained for effective use of Health Communication Strategies and encouraged by seniors to use them frequently. 
Towards Excellence: An Indexed, Refereed \& Peer Reviewed Journal of Higher Education / Dr. Megha Sidhpura \& Dr. Anjali Pahad / Page 482-495

Findings highlighted requirements to build and maintain the accessibility of proper infrastructure facilities like electricity, building, TV, internet etc. to overcome barriers for the front-line health workers.

According to the researcher, support and motivation from authorities besides systematic monitoring and evaluation for use of Health Communication Strategies is most critical for effective Health Communication process which is mainly missing in Chhotaudepur. In absence of proper supervision, monitoring and evaluation, the ASHAs would not be able to utilize Health Communication Strategies at its utmost potential, therefore, IEC committee and or supervisor should be responsible to control barriers in this regard. They should prepare ASHA Facilitators on these aspects and Female Health Workers can also be involved in the process of monitoring the use of Health Communication Strategies. 
Towards Excellence: An Indexed, Refereed \& Peer Reviewed Journal of Higher Education / Dr. Megha Sidhpura \& Dr. Anjali Pahad / Page 482-495

\section{References}

Achyut, P., Benson, A., Calhoun, L. M., Corroon, M., Guilkey, D. K., Kebede, E., ... Winston, J. (2016). Impact evaluation of the Urban Health Initiative in urban Uttar Pradesh, India. Contraception, 93(6), 519-525. https://doi.org/10.1016/j.contraception.2016.02.031

Arya, K., (2016)Information Communication Technology Used By Health Care Worker (Asha) Of Uttarakhand.International Journal of Advanced Research, 4 (6), 1897-1902 http://dx.doi.org/10.21474/IJAR01/681http://www.journalijar.com/uploads/653 IJAR10661.pdf

Government of Uttar Pradesh. (2008). Behaviour Change Communication (BCC) Strategy for NRHM in Uttar Pradesh | 1. 156.

http://www.sifpsa.org/digitization/bce strategy uploading.pdf

Bora Devajit (2016) Development and designing of health communication policies a case study of Assam, Ph.D. Thesis from Gauhati University http://hdl.handle.net/10603/201229

Chib, A., Yi Jia, C., Lin Chieh Lynette, L., ChiahHwee Cheryl, N., Chin Kee, T., \&Vlv, K. (2012). The Hope of Mobile Phones in Indian Rural Healthcare. Journal of Health Informatics in Developing Countries Www.Jhidc.Org, 6(1).

http://www.jhidc.org/index.php/jhidc/article/viewFile/81/118

Kaur, M., Jaswal, N., \&Saddi, A. K. (2017). Evaluation of a women group led health communication program in Haryana, India. Evaluation and Program Planning, 65, 12-19 https://doi.org/10.1016/j.evalprogplan.2017.05.019

Ministry of Health and Family Welfare, Government of India. (2019). AnnualReport 201819.Chapter-17 Information, Education \& Communication, https://main.mohfw.gov.in/sites/default/files/17\%20ChapterAN2018-19.pdf

Ministry of Health and Family Welfare, Government of India. (2005). Guidelines: Accredited Social Health Activists ( Asha). 1-11.

http://www.nrhmharyana.gov.in/WriteReadData/Guidelines/ASHAguidlines/ASHAguidlines/ $\underline{\text { ConceptandOperationalGuidelinesofASHA.pdf }}$ 
Towards Excellence: An Indexed, Refereed \& Peer Reviewed Journal of Higher Education / Dr. Megha Sidhpura \& Dr. Anjali Pahad / Page 482-495

Murthy, N. \&Vijayaraman, G. (2012) Role of Mobile Phone in Health Worker's Work

Routine http://dx.doi.org/10.2139/ssrn.2167757

Nkanunye, C. \&Obiechina, G. (2017) Health Communication Strategies as Gateway to

Effective Health Promotion and Well-being. J Med Res Health Educ 2017, Vol.1 No.3: 13.

https:/www.imedpub.com/articles/health-communication-strategies-as-gateway-to-effectivehealth-promotionand-wellbeing.php?aid $=21312$

National Health Mission-Implementation framework (2012-2017)

https://nrhm.gujarat.gov.in/implementation-framework-plan-of-action.htm

National Health Mission (NHM) Manual for District- Level Functionaries (2017)

https://darpg.gov.in/sites/default/files/National\%20Health\%20Mission.pdf

Sidhpura, M. \&Pahad, A. (2020).Use of Health Communication Strategies under National

Health Mission (NHM) by the Frontline Health Workers: a research in Chhotaudepur (Tribal)

District of Gujarat, India. Adalya Journal, Vol. 9, Issue 10, pp. 480-494

http://doi.org/10.37896/aj9.10/047

Thakur, J., Jaswal, N., \& Grover, A. (2017). Is focus on prevention missing in national health programs? A situation analysis of IEC/BCC/Health promotion activities in a district setting of Punjab and Haryana. Indian Journal of Community Medicine, Vol. 42, pp. 30-36.

https://doi.org/10.4103/0970-0218.199795

\section{Dr. Megha Sidhpura (Assistant Professor)}

Department of Extension and Communication, Faculty of Family and

Community Sciences

The Maharaja Sayajirao University of Baroda, Vadodara

sidhpura.megha-extcomm@msubaroda.ac.in

ORCID ID https://orcid.org/0000-0003-4445-1500

\&

Dr. Anjali Pahad (Professor and Head)

Department of Extension and Communication, Faculty of Family and

Community Sciences

The Maharaja Sayajirao University of Baroda, Vadodara

pahad.anjali-extcomm@msubaroda.ac.in 